\title{
El mundo poético de "Warma Kuyay" por
}

Paulina Matta de Rodrígucz

Lirismo.

En la primera línea del cuento (1), sorprende su carác. ter fuertemente lírico. De:

Noche de luna en la quebrada de Viseca

no surge la descripción que podría esperarse en una narra. ción. Es un verso, por su estructura, su ritmo, su calidad melódica. Y es verso lírico, pues hace presente una realidad espacio y tiempo- pero desrealizándola; afirmando su fuerza expresiva no tanto en lo semántico, como en lo formal, pre. cisamente aquello capaz de conllevar un "temple de ánimo": Está el paralelismo de los dos hemistiquios del verso, el ritmo regular (1-4-8-12), el paisaje dado por la calidad de los sonidos (acentos rítmicos en vocales oscuras, o-u, cuando se trata de la noche; en vocales claras, a-erscuando se trata de lo iluminado). Surge de todos esos elementos formales, más propios de la lírica que de la narración, ese espacio desrealizado y un temple de ánimo que tiende a algo lento, pendular, contenido; a la melancolía, es decir, a aquello que nace ante un pasado ya irrecuperable.

Causa del lirismo: perspectiva del recuerdo.

Esta desrealización del paisaje, expresada en una estructura eminentemente lírica, proviene de la perspectiva en que se narra Warma Kuyay: es la perspectiva del recuerdo, profundamente ligado a la melancolía. Si las cosas han perdido su concreción, se debe a que están lejanas en el tiempo y en el esnacio. Es esta perspectiva lo que da carácter lírico a lo narrado, perdiendo así importancia lo que es acontecer, lo

'1) Citamos por: JOSE MARIA ARGUEDAS. "Warma Kuyay", en Agua. Ediciones Nuevo Mundo, Lima 1961; pp. 83-90. 
que es propio de la narración, para recaer en lo que ese acontecer revela: un modo de experiencia, revelado por esa misma perspectiva de lejania. Hay distancia en el espacio y en el tiempo: la acción sucede en la niñez y luego, sin continuidad, en la juventud. $Y$ sucede en la comunidad indígena $y$ luego, sin continuidad nuevamente, en la ciudad.

Espacio y tiempo discontinuos, expresión de un modo de experiencia.

Este espacio y tiempo discontinuos expresan lo que es fundamental en Warma Kuyay: el elemento de distancia, de lejania, que de ser elemento de espacio y tiempo, acción y personajes (como se verá más adelante), pasa a ser expresión de un modo total de experiencia que estructura todos los clementos del cuento. Este modo de experiencia es la situación vital de estar marginado.

El personaje principal, Ernesto, participará de dos realidades diferentes, determinadas en el espacio, el tiempo y el afecto. En su niñez, en Viseca, estará frente a una realidad amada: la comunidad indígena. En su juventud, en la ciudad, estará frente a una realidad rechazada: la del blanco. Realmente participa de ambas, pero la manera como él las experimenta es aquella de sentirse al margen tanto de una como de otra. Es la de sentirse fuera, finalmente, de toda vida, de todo pertenecer $y$ poseer.

Valor del acontecer dado por perspectiva del modo de experiencia.

La historia del amor de Ernesto por Justina adquiere todo su valor precisamente desde esa perspectiva del estar al margen. Vale no como acontecer, como un lejano "amor de niño", sino como expresión, en la niñez, de aquello mismo que se soporta en la juventud: la marginalidad. Lo que importa no es lo sucedido en la niñez, sino el sentimiento que permanece aún en otra circunstancia, como es la vida final en la ciudad. Esta es sólo la cúlmine y punto máximo de aquello que se había esbozado en ese "amor de niño": el quedar fuera, ese cstar vitalmente lejos de lo que se ama.

Contacto de $E$. con la realidad: sentir y conocer.

Esta dinámica de estar al margen y sin embargo amar, de lejanía en el estar e intimidad en el afecto, es lo que determina la manera de contacto que Ernesto tiene con la rea- 
lidad total y con cada uno de sus elcmentos. Y es lo que determina también su vida como conflicto doloroso.

Cercania por el sentir.

En la manera de Ernesto de aprehender la realidad juegan ambas fuerzas. Por su sentir, Ernesto está de tal manera ligado a la realidad, que es incapaz, en esc sentir, de desligar afecto y cosa. Tanto amor, como odio o temor, aparccen tan profundamente unidos a cicrtos objetos, que se les superponen como parte integrante de ellos mismos, sin relación de causa a efecto. Al hablar de su amor por Justina, dice Ernesto:

su boca llamaba al amor y no me dejaba dormir. (...); sus pechitos parecian limones grandes, y me desesperaban.

(p. 87)

Ei sentimiento y la realidad que lo causa se dan en Ernesto con tanta proximidad, que llegan a superponerse a través de esa conjunción " $y$ ". Y lo mismo sucede en otros niveles: el temor está indisolublemente unido al cerro negro, el Chawala; el desprecio, a esa "cara de sapo" del Kuttu.

\section{Lejania en el conocer: sonido.}

Sin embargo, si por el sentimiento Ernesto está así unido a su circunstancia, su lejanía y su estar al margen de ella están claramente revelados por su manera de conocerla. El elemento a través del cual Ernesto setrepresenta la realidad es fundamentalmente el sonido; su contacto con ella es a través del escuchar. Sabe de Justina por sur canto (p. 83-84), por su risa (p. 89); la unidad de los indios está dada por el bailar juntos al son de la música (p. 83); parte del paisaje está encarnado en sonido (eucaliptos-sonido, p. 84; se sabe del viento por su silbido y del río por su canto áspero, p. 87); el mai presagio llega a través del canto de la paca-paca ( $p$. 84); la alegria del Kutu aparece a través de su voz semejante a la del león (p. 86); la ciudad es "bullicio", (p. 90).

El escuchar aparece así como una manera de conocer la realīad, de penetrar en ella. Pero es la manera de alguien que está fuera, que no participa. Ernesto sabe de las cosas que ama porque las escucha, pero él está siempre lejos ("oyendo su risa, mirándola de leiitos", p. 89). Es un conocer sin participar. Es como si todo careciera de esa concreción que permite tocar, poseer. Las cosas llegan a Ernesto desmaterializadas en sonido. Es sonido que señala distancias, no proximidad; que señala inasibilidad. $\mathrm{Y}$ eso es Ernesto: el 
que conoce y ama, pero sin pertenecer ni poseer; el que recibe el sonido de las cosas, pero no las cosas mismas.

Esta manera de existir en la realidad, (cercanía por el afecto, lejanía en el eștar), es lo que también revela el acontecer - ese amor de niño-y las relaciones de Ernesto con los demás personajes.

El acontecer: conflicto entre realidad del Kutu y de Ernesto.

Ernesto ama a Justina. Por tal situación está unido al Kutu, que también la ama. Sin embargo, Ernesto sabe que su amor es irrealizable:

y no creia tener derecho todavia sobre ella; sabia que tendria que ser de otro, de un hombre grande....

El conflicto del acontecer en el cuento no nace entonces de la no realización de ese amor, que se sabe imposible por su naturaleza misma. Nace de la unión y choque de esas dos realidades que son el amor de Ernesto y el amor del Kutu. Realidades que si tienen puntos de unión, tienen significado absolutamente diferente, dada la situación vital diferente del Kutu y de Ernesto.

Realidad del Kutu.

El Kutu pertenece al mismo círculo que Justina, participa de su misma realidad, tanto en raza como en edad. Su amor tiene el significado preciso de amor de hombre a mujer, y es realizable en la medida en que tal amor lo es. Su frustración se debe a una situación social, que en cierta manera es momentánea; es una circunstancia, un accidente, y no un producto necesario del ser del Kutu. Es la situación social de opresor-oprimido (Don Froylán-Kutu) lo que determina la frustración de ese amor. De tal situación nace la impotencia del Kutu, que lo lleva a una venganza que no es tal; venganza que nace de su debilidad: al no poder castigar al que impide su amor, transfiere el odio a algo en que representa la persona odiada, y así maltrata a los becerritos de don Froylán en vez de a don Froylán. Ernesto también participa de esa impotencia, pero en él tiene un significado diferente, por nacer de una realidad diferente, como es el círculo en que él se mueve y desde el cual ama a Justina. La situación del Kutu es claramente definida: pertenece a la realidad indígena. 
De ahi que sus relaciones con las personas de su misma raza, o de la blanca, sean claras también: es aceptado por su circulo; es vejado por don Froylán, por ser un inferior; es amado por la tía de Ernesto, como si fuera su hijo (p. 89). Ernesto, en cambio, está en una posición ambigua, que lo diferencia del Kutu y hace menos definidas sus relaciones con indios y blancos. El Kutu mismo siente su radical diferencia con Ernesto, a pesar del amor común, lo que le hace exclamar ante el amor del niño:

— ¡Verdad! Así quieren los mistis.

Realidad de Ernesto.

(p. 87)

Ernesto participa de la realidad del indio y de la del blanco, pero esa participación se da como un no ser aceptado $\mathrm{y}$ un sentir que no se pertenece cabalmente a ninguna de las dos. $\mathrm{Y}$ esto dificulta sus relaciones con ambos lados, y les da un significado diferente al que tienen en cl Kutu.

El amor de Ernesto a Justina no tiene el valor de amor de hombre a mujer, como en el caso del Kutu. Justina sig. nifica para él todo un modo de realidad, y no sólo una mujer; es asi que, ido el Kutu, Ernesto puede tener una "casi felicidad" (p. 89), aún sin haber logrado su amor, precisamente por estar en la realidad amada:

Y como amaba a los animales, las fiestas indias, las cosechas, las siembras con música y jarawi, viví alegre en esa quebrada verde y llena del calor amoroso del sol.onverson

El amor a Justina, más que amor a una mujer, es amor a una realidad. Pues el dolor no nace al perder a Justina, que nunca la tuvo, sino al perder la realidad amada. No es el no poder realizar el amor a Justina lo que causa el dolor, sino el no poder realizarse en la realidad amada, el no poder poseerla ni pertenecerla. Ernesto había vivido alegre:

Hasta que un día me arrancaron de mi querencia, para traerme a este bullicio, donde gentes que no quiero, que no comprendo.

(p. 90)

En ese "arrancaron" está toda la violencia hecha al ser de Ernesto con tal trasplante desde su "querencia", su lugar querido, a algo que es fundamental inarmonia: bullicio, desamor, incomprensión. 


\section{Conflicto del acontecer.}

Del choque de esas dos realidades, el mundo del Kutu y el mundo de Ernesto, y no de la imposibilidad del amor del niño, surge el verdadero conflicto del cuento.

El clímax de este conflicto, y el momento que mejor lo revela, es aquel de la venganza en los becerritos de don Froylán. El Kutu puede castigarlos, porque para él son sólo los animales del patrón, objeto adecuado donde descargar su odio impotente. Y puede vengarse en ellos porque su amor por Justina es simplemente amor a mujer, sin involucrar más: para él no hay relación alguna entre la mujer y la realidad circundante, entre su amor a una y su odio a lo que la otra representa. Por eso también puede olvidar a Justina; para él es una mujer. El no lograrla significa sólo no lograr a una mujer, y no, como en el caso de Ernesto, la pérdida de toda una realidad, el estar siempre en la misma situación de le. janía de lo amado y de lo que se siente propio. Es así que Ernesto puede decir:

El quizás habrá olvidado: eșá en su elemento;

(p. 90)

Ernesto, en cambio, no puede realizar su odio en esa misma venganza, porque su amor involucra más que un amor a mujer. Su amor es para toda esa realidad que Justina representa y que abarca, además de ella, a los becerritos castigados, las tierras, los cantos. Es imposible, entonces, que haga recaer su odio $y_{\text {su }}$ deseo de vengar a lo amado precisamente en lo "mismo que ama: es ese el conflicto profundo de Ernesto, que estructura el acontecer. $Y$ es de ahí que nace su ruptura con el Kutu; fundamentalmente del diverso significado de sus amores: amor a Justina, en el Kutu; amor a la realidad representada por Justina, en Ernesto. Nuevamente de dos realidades que no se comunican, que mutuamente se marginan, surge el conflicto.

El cuento en su totalidad está estructurado en base al juego entre esas dos realidades; más bien, entre las dos perspectivas (Kutu-Ernesto) de una misma realidad: el amor a Justina. De la solución de este juego surge la situación vital de Ernesto y del Kutu.

Marginalidad de Ernesto.

Si el amor de Ernesto a Justina tiene un significado diferente al del Kutu por Justina, también su situación ante ella 
difiere. Decíamos que el Kutu y Justina pertenecen al mismo círculo, y que Ernesto está en otro círculo, desde el cual la ama. Áma desde cierta distancia. En varios niveles se da esa lejanía y marginalidad. Estos diferentes planos están marcados por diferencia de raza: al llamado de Ernesto se le responde:

- ¡Déjame, niño, anda donde tus señoritas!

(p. 83).

Y también por diferencias de edad. Ernesto es un niño; no puede penetrar a ese ámbito donde los amores se realizan, privativo de los mayores.

-¡Déjame, niño Ernesto! Feo, pero soy buen laceador de vaquillas y hago temblar a los novillos de cada zurriago. Por eso Jus. tina me quiere.

(p. 83)

Al ser rechazado del círculo comunitario y del círculo de los mayores, es rechazado de la alegría, que se transforma en una burla para él. Este rechazo alcanza su expresión máxima en la ronda, que será resumen de la situación vital de marginalidad de Ernesto:

Yo me quedé fuera del círculo, avergonzado, vencido para siempre.

(p. 83)

Está primero el elemento físico: círculo, lo cerrado c impenetrable; luego su proyección en lo afectivo: el estar fuera del círculo produce vergüienza, precisamente aquello que se siente al estar marginado, expuesto, sin el resguardo y ocultamiento que prōduce elipenteneceróalalgo, el formar parte. $\mathrm{Y}$ todo eso no queda como una sensación momentánea, sino que se proyecta al futuro como signo de derrota.

Estructura de la realidad y de la obra: círculos.

La realidad de Ernesto, y finalmente la realidad de la obra, se estructura sobre la base de estos círculos que lo van dejando al margen. Está primero el círculo donde pueden convivir el Kutu y Justina, simbolizado en la ronda. Luego Ernesto se aleja hacia el molino viejo, concretando su soledad interior en soledad física. El círculo de la ronda es rodeado, desde la nueva perspectiva de Ernesto, por el círculo del paisaje. Pero es un espacio que nuevamente aparece desrealizado: las paredes blancas son nubes en movimiento, los eucaliptos de la huerta son sonido (p. 84). Todo es realidad que se escapa, que no quiere quedarse fija y sustentadora; que, finalmente, no lo acepta y lo deja al margen, de nuevo 
fuera de este nuevo círculo. Desde ahí tiene la verdadera perspectiva de la ronda; es de distancia y alejamiento, y tanto, que llega a desrealizar a las personas transformándolas en "estacas de tender cueros" y en"puntito negro" (p. 84).

Pero no acaban aquí los círculos que lo van dejando al margen. Desde la perspectiva final del cuento (la juventud en la ciudad, sin continuidad con la niñez en Viseca; - tiempo y espacio discontinuos-), aparece el mundo de la comunidad indígena y de Ernesto- niño como otro y mayor círculo que se sigue contemplando desde fuera, el nuevo "fuera" que es el espacio-ciudad y el tiempo-juventud. La niñez aparece como algo redondo y acabado, lejano en espacio y tiempo, sin ligazón con el presente desde el que se narra. Lo que une las dos situaciones, y las hace idénticas, es ese modo de experiencia de sentirse al margen, causa profunda del dolor. Es el ser mestizo, inaceptado en la realidad indígena de la niñez y en la realidad blanca de la juventud.

Impotencia como expresión de marginalidad.

Su estar al margen es percibido por Ernesto como impotencia: un no poder realizarse en lo amado, un no poder lograr lo que se quiere. En primer lugar, no puede realizar su amor, porque tal cosa pertenece, como decíamos, al ámbito de los mayores. Y está precisamente el "gran mayor", don Froylán, amo y autoridad, como la causa principal y fuerte símbolo de lo que determina la impotencia de Ernesto y del Kutu, aunque ambas tengan significado-diferente (en cl primero se debe a suser mestizo; en el segundo a la relación opresor-oprimido).

Se odia a don Froylán como origen de la impotencia, de la imposibilidad de realizar el amor. Y al mismo tiempo se le teme porque, después de todo, es la autoridad, aunque no dé lo que se espera de ella en un régimen paternalista como es el de las comunidades indígenas. Odio y temor parecen tener siempre, en los cuentos de Arguedas, esa misma raíz de reacción ante la autoridad opresora. Tal unidad está claramente simbolizada en los cerros negros que aparecen con frecuencia en su obra, en este caso el Chawala, que unen temor. $y$ odio:

el cerro, medio negro, recto, amenazaba caerse sobre los alfalfares de la hacienda. Daba miedo por las noches;

(p. 84).

miré al "Chawala", que parecía terrible y fúnebre en el silencio de la noche. 
- ¡Kutu: cuando sea grande voy a matar a don Froylán!

Don Froylán, que impide la realización del amor, y que produce odio, impide también la realización del odio en la venganza. Hay impotencia en el amar y en el odiar. Y eso por el temor. Surge entonces esa venganza de los débiles, que es más bien un desquite. Pero luego de la venganza y de su alejamiento de la comunidad indígena, el Kutu continúa perteneciendo a la misma realidad que siempre ha habitado, con un lugar preciso en ella:

aunque maula, será el mejor novillero, el mejor amansador de potrancas, y le respetarán los comuneros.

Ernesto, luego de rechazar la venganza y de pedir perdón al becerrito, supera lo oscuro y amargo, la angustia causada por el herir lo amado

una pena negra, invencible, se apoderaba de mi alma.

La sal de las lágrimas siguio amargándome largo rato.

Recupera así lo que es vínculo amoroso y maternal, luminosidad, ternura y dulzura:

Y una ternura sin igual, pura, dulce, como la luz en esa quebrada madre, alumbró mi vida.

(p. 89)

Persistencia final del estar al margen.

Tal recuperación de la felicidad por el amor queda, sin embargo, encerrada en el mundo redondo de la infancia. El sentimiento vital de estar al margen, de soledad, temor, impotencia, que había coexistido con la línea apasionada de amor y odio, que casi lo superaba ("Otra vez el corazón se sacudía como si tuviera más fuerza que todo mi cuerpo", p. 87), es lo que llena, finalmente, el presente desde el cual se narra. El ser ajeno es lo que habia definido la infancia de Ernesto; el ser ajeno es lo que define su presente. Es por eso que no puede olvidar su "amor de niño": en el fondo, lo sigue viviendo, sigue estando al margen de lo amado.

En un último y definitivo paralelo con el Kutu, que resume la diferencia que el amor a Justina tuvo para ambos, y la distancia que siempre hubo entre ellos, dice: 
El Kutu en un extremo y yo en otro. El quizás habrá olvidado: está en su elemento; (...) Mientras yo, aquí, vivo amargado y pálido, como un animal de los llanos fríos, llevado a la orilla del mar, sobre los arenales candentes y extraños.

(p. 90)

La estructura misma de esas líneas expresa con claridad el estar inalterable de Ernesto, que sigue día a día, sombrío y doloroso. Las frases se suceden una a otra, monótonamente, con un ritmo plano, sin altibajos, sin apasionamientos ya. Indican con la misma claridad que lo semántico, el vacío derrotado del trasplantado. El único elemento que sobresale es ese fuerte "aquí": un señalar el lugar. Es que todo se trata de lugares, de un estar fuera, de un estar equivocado, de un no encontrar el lugar propio. Un desarraigo tan fundamental, que se alude a él como a la total imposibilidad de adaptarse de los animales, cuya constitución está hecha para determinados climas. No se habla de imposibilidad de asimilar costumbres, sino algo tan primigenio como es el clima. En el fondo, es un problema de amor y, por ser de amor, de comprensión: se podía ser alegre, aunque melancólicamente, en la "querencia", allí donde se ama. La ciudad, en cambio, es la cúlmine y símbolo de ese no pertenecer, del amor que no puede desarrollarse ("donde gentes que no quiero, que no comprendo", p. 90), de lo que rechaza y no permite asentarse ("candentes"), de lo que está fuera ("extraños").

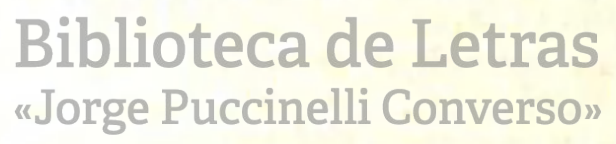

(*) Este trabajo fue considerado el mejor entre los preparados por los alumnos del curso de "Interpretnción de Textos Litcrarios", dictado por el Dr. Alberto Escobar, en el año académico de 1964 